\title{
HISTORIOGRAFI ISLAM: TELAAH SEJARAH DALAM MUQADDIMAH AL- KAMIL Fi AL-TARIKH IBN ATHIR AL-JAZARI
}

\author{
Ahmad Zainuri \\ Magister Sejarah Peradaban Islam, UIN Sunan Kalijaga Yogyakarta \\ ahmadsultanzain1986@gmail.com
}

\begin{abstract}
This article will describe a work of a prominent historian during the Zengid dynasty under the Seljuk dynasty, namely Ibn al-Athir al-Jazari. The historian who emerged in the late classical Islamic period and towards the middle is a figure who has given birth to monumental works in the field of history, namely Al-Kamil Fi Al-Tarikh and several other books. The focus of this study is to examine the work of Ibn Al-Athir in his Muqaddimah. Which the author will describe by explaining the biography, the work of Ibn Athir and the study of the work of Al-Kamil fi Al-Tarikh. The method that the author uses is the historical historiography method. This article examines more than the historiographical study of Ibn Athir himself. The results of the study show that Al-Kamil fi Al-Tarikh is a monumental work in Islamic history. many meanings can be taken in this great writing of Ibn Athir. Apart from Ulama, he is a historian, so that the nuances of his historical writings are full of Islamic treasures, the motivation to write history and what lessons can be learned behind the historical events that occurred, this is the most important. The point is that history must be written thoroughly, not disjointed, so that it appears that history is always continuous, and is not blackened or obscured, omitted in the periodization of history, write as it is and take its ibrah as a life lesson.
\end{abstract}

Keywords: Islamic Historiography, Muqaddimah, Al-Kamil fi Al-Tarikh

Abstrak: Artikel ini akan menjelaskan tentang sebuah karya dari sejarawan terkemuka pada masa dinasti Zengid dibawah dinasti Seljuk, yakni Ibn alAthir al-Jazari. Sejarawan yang muncul pada periode Islam klasik akhir dan menjelang pertengahan ini merupakan sosok yang telah melahirkan karya 
Ahmad Zainuri

monumental pada bidang sejarah, yakni Al-Kamil Fi Al-Tarikh dan beberapa kitab lainnya. Fokus kajian ini ialah pada telaah karya Ibn Al-Athir dalam Muqaddimahnya. Yang akan penulis uraikan dengan menjelaskan biografi, karya Ibn Athir dan telaah karya Al-Kamil fi Al-Tarikh. Adapun metode yang penulis gunakan ialah metode historiografi historis. Artikel ini lebih menelaah daripada kajian historiografi dari Ibn Athir sendiri. Hasil kajian menunjukkan bahwa Al-Kamil fi Al-Tarikh merupakan karya yang monumental dalam kesejarahan Islam. banyak makna yang dapat diambil dalam tulisan agung dari Ibn Athir ini. Selain Ulama, ia sebagai sejarawan, sehingga nuansa tulisan sejarahnya penuh dengan khazanah keislaman, motivasi untuk menulis sejarah dan pelajaran apa yang bisa dipetik dibalik peristiwa sejarah yang terjadi, ini yang paling penting. Intinya bahwa sejarah ditulis harus menyeluruh, jangan terputus-putus, agar nampak bahwa sejarah itu selalu berkesinambungan, dan tidak dihitamkan atau dikaburkan, dihilangkan dalam periodesasi sejarah, tulislah apa adanya dan ambil ibrah-nya sebagai pelajaran hidup.

Kata kunci: Historiografi Islam, Muqaddimah, Al-Kamil fi Al-Tarikh

\section{LATAR BELAKANG}

Sejarah dalam bahasa Inggris disebut history. Secara etimologis, kata ini berasal dari bahasa Yunani, historia yang berarti inkuiri, wawancara, interogasi dari seorang saksi mata, termasuk laporan mengenai hasil-hasil dari tindakan. Dari Yunani, istilah historia masuk ke dalam bahasa Latin. Dalam bahasa Latin klasik, historia maknanya sama seperti dalam bahasa Yunani, dengan tekanan diletakkan dalam pengamatan langsung (direct observation), penelitian (research), dan laporan-laporan hasilnya. Misalnya laporan-laporan sejarawan Tactius yang diamatinya secara pribadi disebut historia, sedangkan laporanlaporannya mengenai periode yang lebih awal (14-68 M) diberinya judul Annales. ${ }^{1}$

Pada masa klasik Yunani dan Romawi, resmi digunakan istilah Annals dan kemudian chronichel. Istilah ini tetap digunakan pada awal abad pertengahan hingga abad ke-16 sebagai istilahistilah utama yang menunjukkan suatu catatan mutakhir mengenai fakta-fakta terpenting atau suatu penulisan sejarah

1 Wilaela, Sejarah Islam Klasik. (Riau: Fakultas Ushuluddin, UIN Syarif Kasim, 2016), 2.

Tamaddun: Jurnal Sejarah dan Kebudayaan Islam, Volume (9), Issue (2), December 2021 
naratif. Pada kedua masa ini, istilah historia belum digunakan untuk menunjukkan peristiwa-peristiwa masa lampau. Dalam perkembangan lebih lanjut, konsep history kemudian memperoleh suatu pengertian baru setelah terjadi percampuran antara penulisan kronikel yang ketat, kronologis dan narasi sejarah yang bebas. Dalam Abad Pertengahan, konsep ini dikenal sebagai biografi-biografi yang disebut vitae. Akan tetapi, baru akhir Abad Pertengahan, istilah historia digunakan dalam arti yang lebih spesifik, yaitu khusus sebagai sejarah. ${ }^{2}$

Historiografi Islam klasik dimulai dari kisah masa Rasulullah Saw hingga keruntuhan Dinasti Abbasiyyah di tangan Hulagu Khan dari Mongolia. Pada masa klasik ini bisa dibedakan dengan beberapa pembabakan, yaitu Pertama, Masa Kemajuan Islam I (650-1000 M); masa di mana ekspansi, integrasi dan keemasan dapat diraih oleh umat Islam masa Rasulullah Saw sebelum wafat pada $632 \mathrm{M}$. Seluruh Semenanjung Arabia tunduk pada kekuasaan masa Rasulullah dan diteruskan masa Khulafaur Rasyidun dan dilanjutkan Dinasti Umayyah dan terkahir Abbasiyah. Kedua, Masa Disintegrasi (1000-1250 M); masa yang terjadi ketika akhir zaman Bani Umayyah, tetapi masa puncaknya pada Bani Abbasiyyah, terutama dalam bidang politik ketika para khalifah mulai melemah di tangan Turki. Daerah yang letaknya jauh dari Damaskus dan Baghdad, melepaskan diri dan bermunculan dinasti-dinasti kecil baru. ${ }^{3}$

Ekspansi masa Rasulullah Saw hanya sekitaran Semenanjung Arab dengan tujuan untuk penguasaan akan wilayah dari kekuasaan Romawi. Namun, setelah masuk pada kepemimpinan Abu Bakar hingga Ali ekspansi mulai dilebarkan hingga ke Damaskus, Baghdad, Babilonia dan wilayah lainnya, terutama ketika masa Umar bin Khattab. Masa ketika Rasulullah Saw hijrah dari Makkah ke Madinah, sesampainya di Madinah $\left(\right.$ Yastrib) ${ }^{4}$ beliau dengan melihat kondisi pedesaan dan beragam

\section{Ibid., 3.}

${ }^{3}$ Setia Gumilar, Historiografi Islam Dari Masa Klasik Hingga Modern. (Bandung: Pustaka Setia, 2017), 135.

${ }^{4}$ Nabi Muhammad Saw sebelum memasuki Yatsrib terlebih dahulu singgah di Quba, tinggal di saa selama 4 hari dan mendirikan masjid Quba, masjid pertama dalam sejarah Islam. Di Quba, Ali bin Abi Thalib menyusul dan bergabung dengan Nabi Muhammad Saw. Dari Quba, terus menuju Yatsrib bersama pengikutnya. 
agama di dalamnya, kabilah dan sukunya, sehingga Rasulullah mengumpulkan para umat dan membuat sebuah perjanjian atau konstitusi bersama, yang kemudian banyak di kenal dengan Piagam Madinah. ${ }^{5}$ Dari perjanjian tersebut kemudian Rasulullah mendirikan negara Islam Madinah.

Ketika masa kepemimpinan di tangan Abu Bakar (632 M), banyak menhabiskan ekspansinya terhadap orang-orang yang tidak mau membayar zakat, murtad dan mengaku nabi, yang kemudian kita kenal dengan Perang Riddah. Ekspansinya yang dilakukan ialah hingga ke negeri Syam. Ketika masa Umar bin Khattab (634-644 M), ekspansi sudah mulai meluas hingga jatuhnya kota Damaskus, menaklukan Persia, Yarmuk (Mesir), Babylonia, dan Iskandaryah. Masa Ustman bin Affan (644-656 M), masa ekspansi berhenti, karena banyak kekacauan yang terjadi hingga Ustman wafat terbunuh. Dengan kemudian naiknya Ali bin Abi Thalib (656-661 M), mendapat tantangan dari Mu'awiyyah-pendukung Ustman. Kemudian Mu'awiyyah melanjutkan kekhalifahan yang kelima, yang dengan membentuk Dinasti Umayyah (661-750 M) di Damaskus. Dan kemudian masa disintegrasi (1000-1250 M) dalam bidang politik menandai akhir Dinasti Umayyah dan munculnya Dinasti Abbasiyyah dengan puncak kekuasaan pada masa Harun ar-Rasyid dan Al-Makmun dengan pusat di Baghdad, yang menandai Islam pada masa the Golden of Age.

Berbicara mengenai perjalanan sejarah dari penulisan sejarah atau yang lebih akrab di kenal dengan Historiografi, akan nampak keanekaragaman corak, bentuk, metode maupun isinya. Memang historiografi merupakan studi tentang keanekaragaman pendekatan dalam penulisan sejarah, di samping sebagai keanekaragaman penafsiran tentang peristiwa-peristiwa masa lampau. Lebih dari itu, historiografi juga diangkat sebagai studi

Nabi Muhammad dan rombongan Muhajirin tiba di Yatsrib pada tanggal 12 Rabi'ul Awwal bertepatan dengan tanggal 17 September 622 M. Sejak peristiwa hijarh itu, nama kota Yatsrib itu diganti menjadi "Madinah".

${ }^{5}$ Perjanjian yang dibuat dan berlaku antara komunitas-komunitas yang ada di Madinah, yaitu Muslim, Yahudi (Bani Nadhir, Quraizhah, Qainuqa') dan komunitas Arab lainnya. perjanjian ini kemudian dikenal dengan "Piagam Madinah" atau "Konstitusi Madinah". Faisal Ismail, Sejarah dan Kebudayaan Islam; Periode Klasik (Abad 7-13 M). (Yogyakarta: IRCiSoD, 2017), 159 \& 163.

Tamaddun: Jurnal Sejarah dan Kebudayaan Islam, Volume (9), Issue (2), December 2021 
Ahmad Zainuri

tentang teknik yang dipergunakan masing-masing sejarawan dalam menuliskan karya-karyanya. Seringkali historiografi atau penulisan sejarah dibedakan dengan metode sejarah. Karena metode sejarah dianggap sebagai suatu proses menguji secara kritis rekaman dan peninggalan mengenai masa lalu. ${ }^{6}$

Membicarakan historiografi tidak pernah melupakan jasa bapak sejarah yang berasal dari Yunani, yakni Herodotus dan pelopor penulisan sejarah secara ilmiah, yaitu Tucydides yang hidup sekitar abad ke-5 SM. Hal ini bisa dimaklumi, sebab begitu besar pengaruhnya warisan budaya Yunani dan juga Romawi bagi kebudayaan dan peradaban Barat modern yang mewarnai dan mendominasi peradaban dunia atau globalisasi, termasuk dalam bidang sejarah. Namun, yang patut disayangkan adalah banyak para ahli sejarah (khususnya para sarjana Barat dan pengekornya) yang melupakan dan "menggelapkan" mata rantai sejarah yang menyelamatkan dan "menyampaikan" peninggalanpeninggalan warisan budaya Yunani dan Romawi tersebut ke alam pikiran dan peradaban modern. Franz Rosenthal menuliskan:

Writing about the writing of history by any particular group or in any particular period means only one thing: To show the development which the concept of history underwent in the thinking and in the scholarly approach of the historians of that particular group or period, and to describe the origin, growth, or decline of the forms of literary expression which were used for the presentation of historical material. ${ }^{7}$

Padahal dapat "dipastikan" dan diyakini bahwa tidak mungkin orang-orang Barat (Eropa) dapat secara langsung mewarisi peninggalan peradaban Yunani dan Romawi kuno yang telah beberapa abad mereka "telantarkan" dan mereka singkirkan sebagai "barang haram" peninggalan kaum Paganisme, tanpa bantuan orang-orang atau sarjana-sarjana Islam masa klasik yang telah menyelamatkan dan secara kreatif mengembangkannya

6 Effendi, Menguak Historiografi Islam Dari Tradisional Konvensional Hingga Kritis-Multidimensi. (Jurnal TAPIs, Vol 9, No1, Januari-Juni 2013), 120.

${ }^{7}$ Franz Rosenthal, A History Of Muslim Historiography (Leiden: E.J. Brill, 1968), 3.

Tamaddun: Jurnal Sejarah dan Kebudayaan Islam, Volume (9), Issue (2), December 2021 
menjadi "kebudayaan Islam". Lalu disampaikannya kembali ke dunia Barat lewat Universitas-universitas Islam yang tersebar di Spanyol seperti Granada, Sevilla, dan Toledo yang banyak dikunjungi para mahasiswa Eropa, di samping juga melalui kontak perang Salib sebagai medianya. Hal inilah yang mendorong timbulnya Renaisans di Eropa yang akhirnya membawa bangsa-bangsa di Eropa memasuki era baru jaman modern yang membawa banyak perubahan dalam berbagai aspek kehidupan umat manusia di dunia. ${ }^{8}$

Kita beralih pada historiografi Islam, dalam historiografi Islam terdapat tiga periodisasi, yaitu klasik, pertengahan dan modern. Penulisan sejarah atau historiografi di dunia Islam diklaim sebagai salah satu peninggalan ilmu terpenting dalam Islam. Sejak pertengahan abad ke-2, penulisan sejarah baik riwayat hidup Nabi Muhammad Saw, maupun sejarah lainnya, sudah mulai digagas menjadi sebuah bangunan sejarah oleh para sejarawan Muslim kala itu. Historiografi awal Islam pada hakikatnya adalah historiografi Arab yang berkembang dalam periode sejak Islam pertama kali disampaikan oleh Nabi Muhammad Saw. Dalam periodisasinya kenapa para sejarawan membagi dengan berbagai periode; pertama, memudahkan pengertian bagi sejarawan, peminat, pembaca dan pemerhati sejarah; kedua, memudahkan klasifikasi dalam ilmu sejarah; ketga, menyederhanakan banyaknya peristiwa sejarah dan memenuhi persyaratan sistematika ilmu pengetahuan. ${ }^{9}$

Dalam periodisasinya, masa klasik antara kisaran tahun 650$1250 \mathrm{M}$, dan masa klasik ini bisa dibedakan dengan beberapa pembabakan, yaitu Pertama, Masa Kemajuan Islam I (650-1000 M); masa di mana ekspansi, integrasi dan keemasan dapat diraih oleh umat Islam masa Rasulullah Saw sebelum wafat pada $632 \mathrm{M}$. Seluruh Semenanjung Arabia tunduk pada kekuasaan masa Rasulullah dan diteruskan masa Khulafaur Rasyidun dan dilanjutkan Dinasti Umayyah dan terkahir Abbasiyah. Kedua, Masa Disintegrasi (1000-1250 M); masa yang terjadi ketika akhir

\footnotetext{
${ }^{8}$ Ibid., 121.
}

9 Setia Gumilar, Historiografi Islam Dari Masa Klasik Hingga Modern. (Bandung: Pustaka Setia, 2017), 129. 
zaman Bani Umayyah, tetapi masa puncaknya pada Bani Abbasiyyah, terutama dalam bidang politik ketika para khalifah mulai melemah di tangan Turki. Daerah yang letaknya jauh dari Damaskus dan Baghdad, melepaskan diri dan bermunculan dinasti-dinasti kecil baru.

Pada periode kedua, yakni abad pertengahan, yakni kisaran tahun 1250-1800 M. Periode ini dibagi dengan dua masa, yaitu, Masa Kemunduran I (1250-1500 M); dan Masa Tiga Kerajaan Besar (1500-1800 M); pada masa ini dapat pula dibagi ke dalam dua fase, yaitu fase Kemajuan II (1500-1700 M) dan Fase Kemunduran II (1700-1800 M). ${ }^{10}$ Terakhir yakni periode ketiga, Periode Modern; periode ini merupakan periode kebangkitan Islam, periode ini terjadi kisaran (1800-sekarang). Berakhirnya ekspedisi Napoleon Bonaparte di Mesir pada tahun 1801 M, membuka mata dunia Islam, terutama Turki dan Mesir, tentang kemunduran dan kelemahan umat Islam di samping kemajuan dan kekuatan Barat.

Dunia Islam seperti dibuat kagum dengan hadirnya representasi dari sebuah kajian keilmuwan yang hebat dari dunia Islam (Timur) yang kemudian bisa pindah ke Barat dengan perkembangan yang begitu sangat pesatnya. Sehingga dunia Islam mengalami inferioritas komplek atau minder terhadap capaian ilmu pengetahuan Barat. Dunia Islam terus berpikir untuk menunjukkan eksistensinya kembali dalam belantika keilmuwan dan keemasan yang pernah diraihnya. Setelah penderitaan yang begitu panjang, Islam mulai menujukkan gelombang pembaharuannya sekitar abad 18 akhir dengan geliat yang luar biasa dari negara Islam termasuk Mesir. Sekitar tahun 1789 M, Mesir sebagai sosok negara Islam yang menunjukkan eksistensinya yang sebenarnya ini terinspirasi dari dunia Barat termasuk Perancis. Penyampaian kemerdekaan akan sebuah kemajuan dengan meretas pemikir pembaharuan awal seperti Rif'at Tahtawi, Jamaluddin al-Afghan, Muhammad Abduh sebagai generasi-generasi yang kagum akan sebuah pencapaian dari Perancis (Barat), yang kemudian mereka mencoba membawa

10 Ibid., 130.

Tamaddun: Jurnal Sejarah dan Kebudayaan Islam, Volume (9), Issue (2), December 2021 
pemikiran dan gagasan Barat dengan dipraktikkan di dunia Islam (Timur). ${ }^{11}$

Dalam bentuk-bentuk metodenya, Historiografi Islam Klasik antara lain; khabar, tarikh, kronik, biografi (thabaqat), nasab dan sejarah umum. Adapun dalam aliran penulisan sejarah Islam klasik pun beragam coraknya. Menurut Husein Nasser dalam Gumilar bahwa perkembangan penulisan sejarah awal masa kebangkitan Islam memperlihatkan tiga aliran yang jelas, yaitu aliran Yaman, Madina dan Irak. Kemudian banyak para penulis sejarah yang tidak memasukkan aliran Yaman dalam aliran penulisan sejarah, karena Yaman banyak menuliskan yang banyak bercampur antara informasi sejarah dengan dongeng atau legenda. Namun, akhirnya bahwa aliran Yaman pun bisa masuk dan dileburkan menjadi satu, meskipun dengan corak dan tema yang semakin beragam. Antara lain aliran-aliran dalam historiografi Islam klasik; Aliran Yaman, Aliran Madinah, Aliran Irak. $^{12}$

Sedikit pengantar sebuah kilasan sejarah yang mengungkapkan tentang sejarah Yunani dan Romawi yang penuh dengan dinamika akan proses dalam perjalanannya. Pada artikel ini penulis akan menyajikan pembahasan pada historiografi Islam klasik, terutama pada tokoh sejarawan klasik (konservatif) yang menuliskan banyak karya yang berjudul $\mathrm{Al}$ Kamil Fi Al-Tarikh yaitu Izz Al-Dīn Abū Al-Asan Alī ibn Al-Athīr atau di lebih dikenal dengan Ibn al-Athir. Secara spesifik tulisan ini akan mengulas tentang; Biografi Ibn Al-Athir Al-Jazari, telaah karya Al-Kamil fi Al-Tarikh dan Pandangan penulis terhadap karya dari Ibn Al-Athir Al-Kamil fi Al-Tarikh.

\section{METODE}

Metode yang hendak penulis gunakan dalam menganalisis muqaddimah al-kamil $f i$ al-tarikh ialah dengan pendekatan historiografi historis. Menurut George Lefebvre dalam Koes

11 Eka Hendry. Perkembangan Pemikiran Modern Dalam Islam. (Pontianak: STAIN Pontianak Press, 2013), xvi.

12 Setia Gumilar, Historiografi Islam Dari Masa Klasik Hingga Modern. (Bandung: Pustaka Setia, 2017), 159. 
menjelaskan bahwa analisis historiografis ialah memandang suatu proses penulisan sejarah adalah bagian dari upaya yang tidak pernah berhenti, yang mengkonsepsikan bahwa hari esok juga akan menjadi bagian dari masa lalu, suatu perjalanan yang melalui proses evolusi bersama lajunya suatu peradaban manusia yang berjalanan seiring dengan berbagai peristiwa yang terjadi yang menandai eksistensi yang terkadang membangun manusia itu sendiri. Tegasnya analisis ini adalah mengonsepsikan suatu peristiwa kesejarahan masa lalu yang memiliki metode yang digunakan oleh penulisnya yang berkaitan dengan aspek-aspek kehidupan yang di dalamnya: bahwa sejarah adalah suatu yang hidup di bawah kondisi-kondisi perubahan. ${ }^{13}$

Menurut Ibn Khaldun dalam Koes bahwa aspek terdalam di dalam sejarah adalah "ia adalah suatu media yang dapat mengantarkan kepada kebenaran, yang melakukan eksplikasi tentang kausa atau asal usul tentang sesuatu.." yakni pengetahuan tentang kenapa dan bagaimana peristiwa itu terjadi. Ibn Khaldun melanjutkan "...ia adalah ilmu yang mulia dan memberikan manfaat banyak dan tujuan yang mulia." Informasi yang dapat digali dari sejarah adalah tentang kondisi-kondisi umat-umat terdahulu, yang ditampakkan di dalam karakter (akhlak) yang mereka miliki, maupun berbagai biografi (sirah) nabi-nabi terdahulu, kronikel tentang para raja, dinasti-dinasti dan politik yang ditempuhnya. Sehingga dalam penggalian informasi ini untuk mencapai tujuan dalam meneladani model-model yang terdapat dalam sejarah ini ialah pada bidang kehidupan religius maupun keduniaan (profan). ${ }^{14}$

Dalam pandangan Ibn Khaldun tadi memberikan sebuah pengantar bahwa di dalam kitab al-Kamil fi al-Tarikh dalam hal ini penulis ambil hanya bagian Muqaddimah nya. Bahwa secara umum bahwa kitab ini menjelaskan tentang sejarah manusia awal yakni nabi Adam hingga masa dinasti-dinasti usai khulafaur Rasyidun. Sejarah dalam rentang tahun yang begitu panjang, tidak

13 Koes Adiwidjajanto, Historicum Calamitatum (Masa-masa Kekalutan) Dunia Islam dalam Historiografi Ibn Athir di dalam Al-Kamil, (Qurtuba: Journal of History and Islamic Civilization, Vol. 1, No. 1, (2017), 30.

14 Koes Adiwidjajanto, Historicum Calamitatum (Masa-masa Kekalutan)

Dunia Islam dalam Historiografi Ibn Athir di dalam Al-Kamil, ibid. 31.

Tamaddun: Jurnal Sejarah dan Kebudayaan Islam, Volume (9), Issue (2), December 2021 
Ahmad Zainuri

lain bahwa memang Ibn Athir selain sejarawan, ia ialah sebagai ulama, sehingga karya-karyanya tidak lepas dari sumber AlQuran dan Al-Hadis. Selaras dengan Ibn Khaldun bahwa di dalam kitabnya juga ada motivasi-motivasi dalam menulis sejarah, manfaatnya dan bisa belajar dari sejarah (ibrah). ${ }^{15}$

\section{HASIL DAN DISKUSI}

\section{Ibn Athir al-Jazari}

Membicarakan sejarawan masa Islam klasik tidak pernah lepas dari seorang sejarawan terkenal Ibn Khaldun. Karyanya yang fenomenal yakni Mukadimah telah menjadi kajian sejarah di berbagai penjuru dunia. Namun, selain Ibn Khaldun, juga masih banyak sejarawan Islam Klasik yang mempunyai karya yang tak kalah megahnya, dia adalah Ibn Athir. Nama Ibn al-Athīr, secara lengkap ialah 'Izz al-Dīn Abū al-Ḥasan 'Alī ibn al-Athīr, lahir 12 Mei 1160, di Jazīrat Ibn 'Umar, JaziraSyria, dan meninggal di bulan Sya'ban tahun 630 H / 1232 M pada usia 75 tahun Mawsil atau Mosul (Iraq). ${ }^{16}$ Di masa mudanya ia belajar banyak subjek, mulai dari bidang ilmu agama, ia belajar Hadits (terutama, di masa yang agak belakangan, sejarah Hadits), fikih dan tafsir. Dia juga menulis sejarah atabeg (mantan perwira tentara Saljuk yang mendirikan dinasti) di Mosul yang disebut al-Bāhir, yang diambil dari pengalamannya sendiri dan dari pengalaman ayahnya, yang menjabat di bawah Zangids Mosul. Di antara karyanya yang lain adalah kompilasi bahan biografi dan silsilah dari penulis sebelumnya. ${ }^{17}$

Ilmu umum yang dipelajarinya mencakup matematika, bahasa, dan musik. Ibn al-Athir muda dikarunia kecerdasan, dengan pikiran yang tajam dan mudah dalam memahami. Selain untuk belajar, masa muda Ibn al-Athir muda juga diwarnai oleh pengalaman yang sama sekali berbeda dari yang sebelumnya ia jalani. Ia menjadi bagian dari pasukan Salahuddin Al-Ayyubi di Suriah pada 1188, tapi bukan sebagai serdadu di Perang Salib,

${ }^{15}$ Azmul Fahimi Kamaruzaman dkk, Ibn al-Athir 's Philosophy of History in Al-Kamil Fi Al-Tarikh. (Jurnal Asian Social Science, vol 11, No 23, 2015), 32.

16 https://delphipages.live/id/sejarah-dunia/sejarawan/ibn-al-athir, (Diakses, 21 Maret 2021).

17 https://www.britannica.com/biography/Ibn-al-Athir (Diakses, 21 Maret 2021).

Tamaddun: Jurnal Sejarah dan Kebudayaan Islam, Volume (9), Issue (2), December 2021 
Ahmad Zainuri

melainkan pencatat peristiwa konflik, layaknya wartawan perang di masa kini. Salahuddin kala itu sudah dikenal sebagai panglima perang Muslim terkenal yang tengah melawan pasukan Salib dan mempunyai pendukung di berbagai wilayah, termasuk di Irak, tempat di mana Ibn al-Athir tinggal. Berdasarkan pengetahuan, pengalaman dan bacaannya selama bertahun-tahun, ia mulai menulis tentang peristiwa-peristiwa sejarah. Al-Kamil fi Al-tarikh (Sejarah Lengkap) adalah karya utama Ibn al-Athir . ${ }^{18}$

Ibn al-Athir selain ahli dalam bidang ilmu lain, seperti figh, mantiq dan lainnya, ia juga merupakan ahli sejarawan klasik yang mempunyai spesial pada bidang kesejarahan. Disebutkan oleh Azmul Fahimi bahwa :

The title of al-Athir was given for his expertise in various fields, especially history. His mastery in the field of history stemmed from his passion for the field. Ibn al-Athir scholarship was very much evident in his historical work entitled al-Kamil fi al-tarikh (Mahayudin, 1986, p. 460) and in that he was able to memorise previous and later histories and he possessed extensive knowledge of the Arab nations, festivals etc. ${ }^{19}$

Telah dipaparkan dengan mengutip pandangan Fahimi bahwa Ibn al-Athir adalah sejarawan yang mempunyai karya luar biasa. Dia mempunyai keahlian dalam bidang sejarah yang menjadi basis keintelektualannya. Dia mampu menuliskan sejarah asal-usul dengan kajian yang begitu komprehensif, karena alAthir memiliki daya pengetahuan yang luas tentang sejarah negara-negara Arab.

Namun, sebenarnya beliau memiliki sebuah nama yang cukup panjang, tapi banyak orang yang mengenal hanya nama pendeknya saja, yakni Ibn al-Athir. Dan dia mempunyai dua saudara, satu kakak dan satu adik, jadi al-Athir itu anak kedua dari tiga bersaudara. Keluarga besarnya berasal dari suku Arab yakni Bani Shayban, dan sekaligus keluarga Al-Athir merupakan keluarga kehormatan dan berkaitan erat sebagai administrasi

18 https://www.republika.co.id/berita/qj56om366/ibn-alathir-sejarawanterkemuka-abad-pertengahan-islam (Diakses, 21 Maret 2021).

19 Azmul Fahimi Kamaruzaman dkk, Ibn al-Athir 's Philosophy of History in Al-Kamil Fi Al-Tarikh. (Jurnal Asian Social Science, vol 11, No 23, 2015), 28.

Tamaddun: Jurnal Sejarah dan Kebudayaan Islam, Volume (9), Issue (2), December 2021 
Ahmad Zainuri

negara zaman Zangid. Dalam Azmul Fahimi menjelaskan dalam biografi bahwa;

Abu al-Hasan 'Ali bin Abi al-Karam Muhammad bin Muhammad bin 'Abd al-Karim bin 'Abd al-Wahid al-Shaibani, whose famed title was Abu al-Hasan and 'Izz al-Din but was better known with the name Ibn al-Athir Jazari, was born on the 4th of Rabi' alAwwal 555H/1160M in al-Jazirah Ibn 'Umar, Mawsil and died in the month of Sha'ban of the year 630H/1232AD at the age of 75 years. Ibn al-Athir had two siblings and he was the second among the three. His elder brother was Majd al-Din while his youngest brother was named Diya' al-Din. The family of Ibn al-Athir was from an Arab tribe of Bani Shayban. Ibn al-Athir 's family was a respectable family and closely related to the state administration in the days of the Zangids. ${ }^{20}$

Ayahanda Ibn al-Athir adalah seorang pentadbir atau administrator dalam sebuah negara atau dinasti di Dewan alMadinah pada era pemerintahan Qutb al-Din Maudud bin Zanki (Zangi) 21 di Mawsil. Ibn al-Athir pernah tinggal di Mawsil (Mosul) yang terletak di Utara Baghdad. Dari sana kemudian di mengembara ke berbagai tempat antaranya, Baghdad, Damsyik, Palestina dan Hijaz. Semasa di Damsyik, ia menumpukan perhatian kepada bidang ilmiah dan penulisan.

Dalam pengembaraan intelektualnya yang panjang, Ibn alAthir banyak belajar dan bergaul dengan berbagai ulama. Ibn alAthir selain menekuni bidang sejarah Arab klasik, ia juga menekuni bidang kajian hadits, fiqh, ushuluddin, fara'id, mantiq dan qira'at. Keahliannya dari berbagai bidang itu berkat pergaulannya yang panjang dengan ulama yang dijumpainya. Meski demikian ia lebih spesifik mendalami dua bidang kesarjanaan, yakni sejarah dan hadits, sampai dikenal sebagai pemuka di bidang hadits. Pada bidang kesejarahan baik sejarah

20 Ibid., 28.

21 Zengid (atau Zangid) adalah sebuah dinasti muslim yang berasal dari Oghuz Turk yang memerintah sebagian daerah Syria dan utara Irak di bawah kekaisaran Seljuk. Dinasti tersebut didirikan oleh Imad ad-Din Zengi (atau Zangi), yang juga seorang Atabeg (pemerintah) di Seljuk Mosul pada tahun 1127. https://id.wikipedia.org/wiki/Dinasti_Zankiyah (Diakses, 21 Maret 2021). 
Ahmad Zainuri

kuno maupun sejarah kontemporer dia merupakan ahli yang Bafizan (mumpuni) pada zamannya. Pada kedua bidang tersebut, Ibn al-Athir mendapatkan namanya di kalangan intelektual pada zamannya. Akan tetapi keahliannya dalam bidang sejarah inilah seakan-akan menutupi kenyataan bahwa dia adalah seorang serba bisa pada bidang kajian keilmuan lainnya. Sebenarnya kaitan pada bidang sejarah dan hadits begitu erat. ${ }^{22}$

Menjelang masa-masa pengembaraan berakhir, Ibn al-Athir bermukim di Mosul atau Mawasil, dengan menyibukkan diri pada penulisan dan penyusunan karya-karyanya sekaligus menggeluti karir di pemerintahan, yang membuatnya bekecukupan dan terpandang. Rumah kediamannya menjadi pertemuan para pengunjung dan penuntut ilmu. Ibn al-Athir wafat pada bulan Sya'ban tahun $630 \mathrm{H}(1233 \mathrm{M}) .^{23}$ Adapun karya-karya Ibn al-Athir al-Jazari ialah; Ibn al-Athir selaku sejarawan Islam klasik yang terkenal dengan karya yang monumentalnya yakni Al-Kami Fi Al-Tarikh ini, tidak hanya menuliskan hanya satu kitab sejarah besar itu. Namun, ia menuliskan banyak karya yang lainnya. Sebagai seorang tokoh besar, dipastikan mempunyai sebuah karya yang melatarbelakangi besarnya tokoh tersebut. Antara lain karyanya:

1. Kitab Al-Labab fi Tahzib Al-Anshab

2. Kitab Usid al-Ghabah fi Marifah as-Sahabah;

3. Kitab Tarikh al-Daulah Al-Atabikiah;

4. Kitab Al-Kamil Fi Al-Tarikh;

Dalam karyanya yang berjudul Al-Kamil merupakan kitab yang muktabar. Kitab itu merupakan salah satu kitab sejarah terbesar yang menjelaskan sejarah permulaan alam hingga sejarah yang berlaku pada tahun $623 \mathrm{H} / 1238 \mathrm{M}$. Kitab ini ditulis berdasarkan kitab At-Tarikh At-Thabari, tetapi mengikuti sebuah corak dan bentuknya tersendiri.

22 Koes Adiwidjajanto, Historicum Calamitatum (Masa-masa Kekalutan) Dunia Islam dalam Historiografi Ibn Athir di Dalam Al-Kamil. (Jurnal Qurthuba,Vol 1, No 1, September 2017), 33.

23 Sidqy Munjin \& Satria Setiawan, Analisis Penulisan Al-Kamil Fi Al-Tarikh Karya Ibn Al-Athir. (Jurnal Rihlah, Vol 6, No 1, 2018), 154. 
Ahmad Zainuri

\section{Muqaddimah Al-Kamil Fi Al-Tarikh}

Dalam Muqaddimah Al-Kamil; Ibn al-Athir mendeskrispikan pembukaan atau kata bagian dari kata pengantar dari Al-Kamil menunjukkan bahwa secara tidak langsung secara detail filsafat sejarahnya untuk pemahaman secara umum dari para pembaca. Menjelaskan secara detail di dalam kata pengantar bertujuan untuk membongkar pertanyaan dalam sebuah prinsip dan metode historiografi atau penulisan sejarah kitab Al-Kamil fi AlTarikh.

Dalam kata pengantar Al-Kamil mengandung empat bagian, misalnya yang pertama, pujian atau memuji, kedua, pendahuluan, ketiga, metode penulisan; cakupan sejarah dan sumber refrensi dan keempat, manfaat dari menuliskan sejarah. Pujian dalam artian ialah memuji kepada Allah, Nabi Muhammad Saw, dan para sahabat nabi (semoga Allah mengampuni mereka) ini text untuk awal dari kata pengantar dalam Al-Kamil. Bagian pertama dalam sebuah pujian kepada Allah dan Nabi-Nya seperti mengucapkan Bismillahi al-Rahman al-Rahim dan di akhiri dengan surat dari Maryam. Dalam Azmul Fahimi menjelaskan:

Such as the pronouncement Bism Allah al-Rahman al-Rahim and later ended with verses from Surah Maryam, "And how many a generation before them have we destroyed! Canst thou (Muhammad) see a single man of them, or hear from them the slightest sound?" and Surah al-A'raf "... His verily is all creation and commandment. Blessed be Allah, the Lord of the Worlds!". 24 Both verses from Surah Maryam and al-'Araf allude to an early understanding on the importance of learning from past stories. According to the interpretation of al-Tabari, verse 98 of Surah Maryam means, did you see and hear the voice of previous people destroyed by God because they followed a false path and do evil to Him. The slightest sound is the soft voice of those who perished due to ungratefulness to His blessings. This verse reminds the ummah of Prophet Muhammad (p.b.u.h.) to immediately repent from sin if

24 “Dan berapa banyak satu generasi sebelum mereka telah kita hancurkan! Dapatkah engkau (Muhammad) melihat satu orang dari mereka, atau mendengar dari mereka sedikit pun suara (berdoa) kepada Allah ? " dan Surah al-A'raf "... Sesungguhnya miliknya adalah semua ciptaan dan perintah. Terpujilah Allah, Tuhan Semesta Alam!".

Tamaddun: Jurnal Sejarah dan Kebudayaan Islam, Volume (9), Issue (2), December 2021 
Ahmad Zainuri

they do not want to perish like previous generations. The interpretation of verse 54 Surah al-A'raf meanwhile is to create and rule cannot be done by anything other than Allah, including worshipped gods and idols because both of them can bring about neither harm nor benefit and cannot create anything or rule anything. ${ }^{25}$

Penjelasan diatas ini merupakan sebuah pengantar dari karya Ibn Al-Athir dalam kitabnya Al-kamil dengan beberapa penjelasan bagian-bagian dari isi kitab dan penggalan surat yang digunakan di dalam kitab tersebut. Tak lain Al-Athir juga menuliskan beberapa bagian yang bermanfaat untuk pentingnya penulisan sejarah dan metodenya, termasuk terciptanya kitab AlKamil beliau tersebut. Dan juga dijelaskan bahwa begitu pentingnya mempelajari sebuah cerita masa lampau sebagai kesejarahan hidup agar lebih baik dan bersyukur atas apa yang Allah berikan dan tidak mengkufuri nikmat-Nya dan segeralah bertobat dan jangan mengulangi lagi seperti umat sebelumnya.

Secara umum dalam kitab Al-Kamil dalam jilid pertama menceritakan sejarah pra-Islam bermula dengan penciptaan alam semesta diikuti oleh sejarah Bible, termasuk cerita-cerita penukaran pada agama Kristen Konstantinopel dan sejarah awal Arab-Islam. Dan di jilid pertama ini juga menceritakan kisah Nabi Adam hingg nabi Ibrahim. Kemudian dalam jilid ini juga membahasa tentang pembinaan Ka'bah di Kota Makkah. Menguraikan bangsa-bangsa terdahulu, seperti Persia, Bani Israel dan Iskandar Zulkarnain. Ia juga dalam jilid ini menjelaskan Raja Roma sehingga pada Raja Heraclius. Kemudian Ibn al-Athir juga membicarakan tentang Arab jahiliyah dan hubungan mereka dengan Persia, Roma dan Habsyah. Jilid pertama ini diakhiri dengan uraian tentang peperangan yang berlaku di antara orang Arab pada zaman Jahiliyah. ${ }^{26}$

Jilid kedua menjelaskan kehidupan Nabi Muhammad Saw dan para sahabatnya, Abu Bakar as-Siddiq dan Umar bin Khattab. Di bab kedua ini diakhiri dengan pembukaan negeri Mesir oleh

25 Azmul Fahimi Kamaruzaman dkk, Ibn al-Athir 's Philosophy of History in Al-Kamil Fi Al-Tarikh. (Jurnal Asian Social Science, vol 11, No 23, 2015), 29.

26 Setia Gumilar, Historiografi Islam Dari Masa Klasik Hingga Modern. (Bandung: Pustaka Setia, 2017), 176. 
Amru bin 'As. Jilid ketiga menjelaskan khalifah Ustman bin Affan dan Ali bin Abi Thalib. Kisah pada jilid ini Ustman dan gerakan pembukuan yang berlaku dalam masa pemerintahnnya di Khurasan, Karman, Sajistan, Afrika dan Spanyol. Jilid keempat membahas sejarah Umayyah, yang pada pertama menceritakan wafatnya Muawiyyah bin Abu Sufyan dan menjelaskan khalifah dinasti Umayyah. Dan selanjutnya ia membahas mengenai pembukaan Islam, terutama di Roma dan pulau-pulau sekitar Laut Mediterania.

Pada jilid kelima, Ibn al-Athir menjelaskan berakhirnya Dinasti Umayyah dan berdirinya Dinasti Abbasiyah. Jilid keenam membahas zaman keemasan Dinasti Abbasiyah masa Khalifah AlMansur, Al-Mahdi, Al-Hadi, Harun al-Rasyid, Al-Amin, AlMakmun, Al-Mutasim dan Al-Watsiq. Jilid ketujuh membincangkan khalifah Al-Watsiq dengan sambungan dari jilid keenam tadi dengan menambahkan cerita khalifah AlMutawakkil, Al-Muntashir, Al-Mustasin, Al-Mutaz, Al-Muhtadi, Al-Mu'tamad dan Al-Muktafi. Jilid kedelapan membahas permulaan Byzantine ke arah Timur di Syria. Menjelaskan dinasti Fatimiyah di Mesir.

Pada jilid kesembilan, al-Athir menjelaskan Dinasti Saljuk dan kawalan atas Abbasiyah. Dan membahas kemerosotan Dinasti Abbasiyah. Jilid kesepuluh menjelaskan peristiwa sejarah pada peristiwa tahun $451 \mathrm{H}$ hingga $527 \mathrm{H}$, yaitu peningkatan kekuasaan golongan Saljuk. Dan keadaan Syam sebelum datangnya Perang Salib, masyarakat Islam di Maghrib, Spanyol dan sisilia. Jilid kesebelas memaparkan peristiwa yang terjadi pada tahun akhir $527 \mathrm{H}$ hingga $583 \mathrm{H}$, peristiwa pengaruh keluarga Zanki dan kejayaan Sultan Nurudin Mahmud dan kejayaan Salah Ad-Din. Dan jilid kedua belas, menjelaskan peristiwa yang terjadi pada $584 \mathrm{H}$ hingga $628 \mathrm{H}$, yang memaparkan Salah ad-Din dan kemenangan terhadap Perang Salib, terutama angkatan yang ketiga.

\section{Telaah Muqaddimah Al-Kamil fi al-Tarikh}

Dalam pandangan penulis dari beberapa pembacaan dari jurnal, kitab dan buku-buku tentang Ibn al-Athir bahwa Ibn alAthir sejak kecil sudah menyukai dunia sejarah dengan sudah lama belajar kepada ayahnya sendiri. Berbagai varian penarasian 
Ahmad Zainuri

dan sebuah dimensi sejarah yang mana menjadi pelajaran yang menciptakan dan dipelihara sebuah arti kecintaannya terhadap ilmu pengetahuannya itu (sejarah). Minatnya dalam menarasikan dengan beragam cakupan membuat sebuah minat tersendiri bagi Ibn al-Athir untuk mengikuti perjalanan setiap sejarah dengan metode naratif-deskriptif.

Ibn al-Athir dalam menjelaskan cerita kesejarahan dalam kitabnya Al-Kamil begitu sangat runtut dengan kejadian yang dilihatnya. Sudah terterangkan diatas bahwa cerita yang ia tulis sesuai perjalanan dan menuliskannya dengan naratif, mengalir dengan keadaan yang ada. Dalam kitab Al-Kalam fi Al-Tarikh, ia menjelaskan dalam sebuah kritikan terhadap sebuah gaya historiografi sejarah dengan analitik, yang kemudian tidak bisa menyampaikan sebuah pesan, sehingga ada sebuah perbedaan tujuan yang menyebabkan intisari isinya tidak diketahui. Menurutnya bahwa menuliskan sejarah itu dengan menarasikan hal-hal yang ada dan dituliskan dengan apa adanya, karena setiap catatan sejarah panjang diceritakan sementara sisa sejarah dirangkum, sehingga menyebabkan peristiwa besar dan terkenal dihilangkan. Menurut Ibn al-Athir menjelaskan dalam Muqaddimah:

falamma ta'ammiltuha ra'aytuha mutabayinah fi tahsil al-ghard, yakadu jawhar al-ma'rifah biha yastahil ila al-'ard,

(Ketika saya menganalisis buku-buku sejarah, saya melihat di dalamnya perbedaan tujuan yang menyebabkan intisari isinya tidak diketahui).

dan dilanjutkan dengan;

famin bayna mutawwilin qad istaqsa al-turuq wa al-riwayat wa mukhtasirin qad akhalla bi kathirin mimma huwa at. Wa ma'a zalik faqad taraka kulluhum al-azim min al-hadithat wa al-mashhur min alka'inat.

(Setiap catatan sejarah panjang diceritakan sementara sisa sejarah dirangkum sehingga menyebabkan peristiwa besar dan terkenal dihilangkan). ${ }^{27}$

27 Al-Imam Ibn Hasan Ali bin Abi Karim Muhammad bin Muhammad bin Abdul Karim bin Abdul Wahid Saybani Ma'ruf "Ibn al-Athir" Jazari biizzuddin, Al- 
Dalam penjelasan lain bahwa, Ibn al-Athir ingin mencoba merekonstruksi sejarah masa lampau dengan daya nalar yang berurutan dan tersistematis, kronologis, kenapa? Agar nampak bahwa sejarah itu memiliki sebuah periodesasi yang jelas dan tidak mengaburkan sebuah kisah yang pernah terlewati dari sebuah masa dengan eksistensi kesejarahan dan kisah masa itu. Karena Ibn al-Athir tidak mau menuliskan sejarah yang terlompat-lompat, sifatnya yang naratif, agar bisa terus terbaca dengan perkembangan zaman dan periodesasi yang runtut tanpa tertutupi dengan kesejarahan yang lain. Karena Ibn al-Athir ingin menuliskan sebuah karya yang menjadi titik yang jelas, jangan tidak mengaburkan setiap kisah sejarah, dan seorang sejarawan harus bisa menuliskan sejarah periode dan diakhiri dengan tulisan tersebut dengan menambahkan sejarah berikutnya. Menurut Ibn al-Athir:

wa sawwada kathir minhum al-awraq bi saghair al-umur allati al-i'rad 'anha awla wa tark tastiruha ahra,

(Mereka menghitamkan lembaran kertas karena kesalahan kecil dan meninggalkannya).

dilanjutkan dengan;

wa qad arrakha kullu minhum ila zamanih waja' ba'dah man zayyala 'alayh. Wa adaf al-mutajaddidat ba'da tarikhi ilayh. Wa sharqiy minhum qad akhal bi zikr akhbar al-gharb wa al-garbi qad ahmala ahwal al-sharq.

(Semua sejarawan mengumpulkan sejarah di setiap periode dan mengakhiri tulisan mereka dengan menambahkan sejarah berikutnya. Untuk sejarawan di timur, mereka tidak menyebutkan peristiwa di barat dan begitu pula sejarawan di barat, mengabaikan situasi di timur). ${ }^{28}$

Kamil Fi Al-Tarikh: Tarikh maa Qobla al-Hijroti al-Nabawiyah Syarifiyah (Beirut: Darul Kitab Al-'Ilmiyah, 1984), 5.

28 Al-Imam Ibn Hasan Ali bin Abi Karim Muhammad bin Muhammad bin Abdul Karim bin Abdul Wahid Saybani Ma'ruf "Ibn al-Athir" Jazari biizzuddin, 6 . 
Implikasi dari perbedaan tersebut menyebabkan isi sebuah karya sejarah menjadi tidak teratur dan tidak jelas, bahkan hingga peristiwa-peristiwa sejarah yang penting diabaikan dibandingkan dengan yang lain. Sehingga menuliskan sejarah harus berurutan yang terkronologis, agar nampak sejarah itu terus berurutan dan berjalan dengan sesuai masa zamannya, dan tidak menutupi atau menghitamkan lembaran kertas yang terjadi dalam sebuah kesalahan kecil dan ditinggalkan oleh mereka. Sikap tersebut menunjukkan bahwa tidak ada upaya untuk memperbaiki atau mengoreksi fakta sejarah yang salah. Keadaan ini membuat isi sejarah tidak lengkap dan penjelasannya kabur.

\section{KESIMPULAN}

Ibn al-Athir al-Jaziri, begitu akrabnya, merupakan sosok sejarawan terkemuka yang lahir di Jazirah. Ibn al-Athir merupakan sejarawan dalam periodesasi sejarah Islam klasik. Ibn al-Athir didudukkan bersama Ibn-Thabari, Ibn Ishaq, Al-Biruni, yang merupakan sejarawan Islam klasik mumpuni dalam berbagai kajian kesejarahan dengan bidang pengembangannya masingmasing. Latar belakang Ibn al-Athir merupakan putra kedua dari tiga bersaudara. Kakanya bernama Majd-al-Din dan sementara adiknya Diya' al-Din. Keluarga Ibn al-athir merupakan keluarga yang mempunyai keturunan atau suku/kabilah dari Arab yakni Bani Shayban. Ayahnya yang pernah bekerja sebagai pentadbir atau administrator negara ketika masa pimpinan Qutb al-Din Maudud, dari Dinasti Zangid, Mosul. Karya Abu al-Hasan 'Ali bin Abi al-Karam Muhammad bin Muhammad bin 'Abd al-Karim bin 'Abd al-Wahid al-Shaibani atau Ibn al-Athir tidak diragukan lagi terutama dalam bidang sejarah Islam klasik, ia telah menulis $\mathrm{Al}$ Kamil Fi Al-Tarikh sebagai karya agungnya dan beberapa kitab sejarah lainnya. Dalam al-Kamil banyak pesan-pesan pelajaran yang hendak disampaikan oleh al-Athir melalui sumber al-Quran dan al-Hadis. Karena sejarah itu memaparkan suatu hal yang bisa memberikan pelajaran hidup, apa yang kemarin buruk, maka jangan diulang untuk yang kedua dan bahkan berkali-kali ke depan. Sehingga makna sejarah ialah adanya ibrah yang dapat selalu kita petik sebagai rumus kehidupan ke depan. 


\section{DAFTAR PUSTAKA}

(2020). Ibn al-Athīr: Sejarawan Arab. https:// delphipages.live/id/sejarah-dunia/sejarawan/ibn-alathir

Adiwidjajanto, K. (2017). Historicum Calamitatum (Masa-masa Kekalutan) Dunia Islam dalam Historiografi Ibn Athir di Dalam Al-Kamil.

Qurthuba,Vol.1,No.1).http://jurnalfahum.uinsby.ac.id/index.ph $\mathrm{p} /$ qurthuba/article/view/145

Effendi. (2013). Menguak Historiografi Islam Dari Tradisional Konvensional Hingga Kritis-Multidimensi. (Jurnal TAPIs, Vol. 9, No. 1). DOI: 10.24042 /tps.v9i1.1579.

Gumilar, S. (2017). Historiografi Islam Dari Masa Klasik Hingga Modern. Bandung: Pustaka Setia.

Hendry, E. (2013). Perkembangan Pemikiran Modern Dalam Islam. Pontianak: STAIN Pontianak Press.

Ismail, F. (2017). Sejarah dan Kebudayaan Islam; Periode Klasik (Abad 7-13 M). Yogyakarta: IRCiSoD.

Ibn, Al-Athir, Al-Imam Ibn Hasan Ali bin Abi Karim Muhammad bin Muhammad bin Abdul Karim bin Abdul Wahid Saybani Ma'ruf. (1984). Al-Kamil Fi Al-Tarikh: Tarikh maa Qobla al-Hijroti alNabawiyah Syarifiyah. Beirut: Darul Kitab Al-'Ilmiyah.

Kamaruzaman, dkk. (2015). Ibn al-Athir's Philosophy of History in AlKamil Fi Al-Tarikh. (Jurnal Asian Social Science, Vol. 11, No. 23). DOI: $10.5539 /$ ass.v11n23p28.

Munjin, Sidqy, S. (2018). Analisis Penulisan Al-Kamil Fi Al-Tarikh Karya Ibn Al-Athir. (Jurnal Rihlah, Vol. 6, No. 1). DOI: https:// doi.org/10.24252/rihlah.v6i2.6910.

Rosenthal, F. (1968). A History Of Muslim Historiography. Leiden: E.J. Brill.

Rasyid, Azhar. (2020). Ibn Al-Athir: Sejarawan Terkemuka Abad

Pertengahan Islam.

https:// www.republika.co.id/berita/qj56om366/ibn-alathir-

sejarawan-terkemuka-abad-pertengahan-islam

Wilaela. (2016). Sejarah Islam Klasik. Riau: Fakultas Ushuluddin, UIN Syarif Kasim. 